\title{
Alterações periodontais associadas às doenças sistêmicas em crianças e adolescentes
}

\author{
Periodontal problems associated with systemic diseases in children and adolescents
}

\author{
Thaís Ribeiral Vieira ${ }^{1}$, Adriana de Castro A. Péret ${ }^{2}$, Luciano Amédée Péret Filho ${ }^{3}$
}

\section{RESUMO}

Objetivo: O objetivo deste estudo foi revisar na literatura a inter-relação entre condições sistêmicas e a ocorrência de doenças periodontais em crianças e adolescentes, destacando-se as manifestações periodontais frequentemente encontradas.

Fontes de dados: Artigos indexados nas bases de dados Medline, Lilacs e Bibliografia Brasileira em Odontologia, nos últimos 20 anos, além de referências clássicas. As palavraschave utilizadas foram: "doença periodontal”, "periodontite", "doenças sistêmicas", "criança” e "adolescente”.

Síntese dos dados: Doenças sistêmicas como hipofosfatasia, histiocitose X, síndrome de Down, síndrome de Papillon-Lefevre, síndrome de Ehlers-Danlos, síndrome de Chédiak-Higashi, leucemias, Aids e as deficiências quantitativas e qualitativas dos neutrófilos estão associadas ao aparecimento de alterações periodontais graves em crianças e adolescentes. Os estudos demonstraram a ocorrência de alteração periodontal na forma de periodontite em crianças e adolescentes com doenças sistêmicas, podendo levar à perda precoce de dentes.

Conclusões: A ocorrência de alterações periodontais é observada em crianças e adolescentes com alterações sistêmicas, que manifestam desde inflamação gengival até formas mais destrutivas, como periodontites e perda precoce dos dentes.

Palavras-chave: periodontite; doenças da gengiva; criança; adolescente.

\section{ABSTRACT}

Objetive: The aim of this study was to review the literature regarding the relationship between systemic conditions and the occurrence of periodontal diseases among children and adolescents, and to highlight the most common periodontal alterations.

Data source: Indexed articles published in the last 20 years on the following databases were searched: Medline, Lilacs, and the archives of the Brazilian Bibliography of Dentistry, in addition to classic references. Keywords included "periodontal disease", "periodontitis", "systemic diseases", "child", and "adolescent".

Data synthesis: Systemic diseases such as hypophosphatasis, histiocytosis X; Down, Papillon-Lefevre, Ehlers-Danlos and Chédiak-Higashi syndromes, as well as leukemia, Aids, quantitative and qualitative neutrophilic deficiencies are associated with severe periodontal alterations among children and adolescents. Several studies demonstrated the occurrence of periodontitis, which can lead to early tooth loss among children and adolescents diagnosed with systemic diseases.

Conclusions: The occurrence of periodontal alterations is observed in children and adolescents with systemic diseases. There are several manifestations, ranging from gingival inflammations to more destructive patterns, such as periodontitis and early teeth losses.

Key-words: periodontitis; gingival diseases; child; adolescent.
Instituição: Pontifícia Universidade Católica de Minas Gerais (PUC Minas), Belo Horizonte, MG, Brasil

'Mestre em Clínicas Odontológicas da PUC Minas, Belo Horizonte, MG, Brasil

2Doutora; Professora Adjunta de Periodontia do Departamento de Odontologia da PUC Minas, Belo Horizonte, MG, Brasil

${ }^{3}$ Doutor; Professor Associado do Departamento de Pediatria da Faculdade de Medicina da UFMG, Belo Horizonte, MG, Brasil
Endereço para correspondência:

Adriana de Castro A. Péret

Avenida Dom José Gaspar, 500 - Coração Eucarístico

CEP 30315-480 - Belo Horizonte/MG

E-mail: adperet@hotmail.com

Conflito de interesse: nada a declarar

Recebido em: 15/12/08

Aprovado em: 15/5/09 


\section{Introdução}

As doenças periodontais consistem em processos inflamatórios de origem infecciosa que acometem os tecidos gengivais (gengivites) e/ou os tecidos de suporte dos dentes (periodontites) $^{(1)}$. Ocorrem como consequência das reações inflamatórias e imunológicas nos tecidos periodontais induzidas pelos micro-organismos do biofilme dental (placa bacteriana), danificando o tecido conjuntivo e o osso alveolar ${ }^{(2-3)}$.

O biofilme bacteriano desempenha um papel importante no processo patogênico. Estratégias para evitar o seu acúmulo por meio de uma boa higiene oral e de raspagem e alisamento radicular devem ser empregadas. Enquanto as bactérias são essenciais para o desencadeamento da doença, a evolução e a extensão do dano periodontal também se relacionam com a suscetibilidade do hospedeiro ${ }^{(2)}$.

O processo patogênico apresenta diferenças na extensão e gravidade no próprio indivíduo e entre indivíduos diferentes. As razões para isso são multifatoriais, podendo estar associadas a condições de risco, como alterações sistêmicas e aspectos comportamentais ${ }^{(2)}$.

A periodontite apresenta alta prevalência em adultos. Em contrapartida, sua ocorrência é rara em crianças, mas não menos importante. Quando se manifesta na população infantil, a doença se desenvolve de forma mais agressiva, destrutiva e de rápida progressão, levando à perda de estruturas de suporte até à perda do elemento dental ${ }^{(1)}$.

O desenvolvimento e a evolução da periodontite são dependentes da resposta imune do hospedeiro ${ }^{(4)}$. Estudos sugerem que indivíduos com início precoce de doença periodontal podem ter doença sistêmica ou apresentar alterações no sistema imunológico ${ }^{(5-10)}$. A hipofosfatasia ${ }^{(11-13)}$, a histiocitose $X^{(6,13-15)}$, a síndrome de $\operatorname{Down}^{(7,16-20)}$, a síndrome de Papillon-Lefevvre ${ }^{(6,11,13,21-}$ ${ }^{23)}$, a síndrome de Ehlers-Danlos ${ }^{(3,6,11,13)}$, a síndrome de ChédiakHigashi $^{(6,13,24-25)}$, doenças que levam à neutropenia ${ }^{(21,25-27)} \mathrm{e}$ disfunções de neutrófilos ${ }^{(6,13,21,25)}$ como deficiência de moléculas de adesão e alterações de quimiotaxia, leucemia ${ }^{(28-31)}$ e Aids $^{(28,32-}$ 37) podem apresentar relação com o aparecimento de alterações periodontais graves em crianças e adolescentes.

Este estudo objetiva apresentar revisão de literatura sobre a relação entre essas condições sistêmicas e a ocorrência de alterações periodontais em crianças e adolescentes.

\section{Método}

Artigos científicos publicados nos últimos 20 anos e referências clássicas abordando a presença de alterações periodontais associadas às doenças sistêmicas em crianças e adolescentes foram pesquisados através dos bancos de dados Medline, Lilacs, BBO. Na pesquisa bibliográfica, foram utilizadas as seguintes palavras em várias combinações: "doença periodontal", "periodontite", "doenças sistêmicas", "criança" e "adolescente".

A busca das fontes de dados incluiu consensos, estudos transversais, estudos longitudinais, estudos de revisão e relatos de casos em línguas inglesa, portuguesa e espanhola. Foram selecionados os artigos relativos a doenças sistêmicas citadas com maior frequência nos periódicos. Após a determinação das doenças a serem abordadas, os artigos selecionados foram previamente analisados em relação a seus títulos e resumos por três avaliadores. A inclusão foi baseada na metodologia utilizada em cada estudo (população de estudo e desenho da pesquisa).

\section{Revisão da literatura}

\section{Hipofosfatasia}

A hipofosfatasia é uma condição hereditária caracterizada por baixos valores sistêmicos de fosfatase alcalina, enzima que participa do processo de formação dos tecidos mineralizados. A hipofosfatasia pode se manifestar clinicamente nos primeiros meses de vida ou na idade adulta. Quando aparece ao nascimento ou nos primeiros anos, leva a falhas no crescimento, deformidades no esqueleto, pneumonias recorrentes, lesões renais e alterações na dentição decídua, como esfoliação precoce dos dentes, particularmente na região anterior, sem estar relacionada com inflamação gengival ${ }^{(11)}$.

A perda prematura dos dentes decíduos é um achado comum, podendo, algumas vezes, ser o único sinal evidente da doença. A perda dos dentes é causada pela presença de hipoplasia cementária, que causa anormalidades na estrutura periodontal e aumenta a suscetibilidade a infecções bacterianas. O cemento radicular é responsável pela inserção das fibras periodontais e participa do processo de reparo após dano à superfície radicular. Em decorrência da hipofosfatasia, os dentes apresentam uma fina camada hipoplásica de cemento com poucas fibras periodontais, o que aumenta a suscetibilidade à doença periodontal na presença do biofilme bacteriano $^{(12)}$.

As alterações patológicas no periodonto se devem aos níveis insuficientes de fosfatase alcalina. Essa enzima é o ponto-chave na produção tanto de osso quanto de cemento. A diminuição da produção e da atividade dessa enzima leva ao acúmulo de fosfato inorgânico, o qual inibe a mineralização. 
Isso determina uma osteogênese e cementogênese defeituosas, além da formação de um sistema de inserção alterado, tornando os dentes mais propensos à esfoliação e as superfícies radiculares mais suscetíveis à colonização bacteriana ${ }^{(13)}$.

\section{Histiocitose X}

A histiocitose $\mathrm{X}$, também conhecida como granulomatose das células de Langerhans, é um distúrbio no sistema retículo-endotelial, resultando em proliferação e disseminação patológica dos macrófagos (histiócitos) ou células de Langerhans ${ }^{(6)}$. As células de Langerhans, no interior do epitélio, participam do desencadeamento da resposta imune, apreendendo o material antigênico proveniente dos microorganismos e levando-o para o tecido linfoide, onde ocorre a apresentação do antígeno para os linfócitos. Os indivíduos capazes de produzir uma resposta imune efetiva podem ser mais resistentes à periodontite do que aqueles cuja resposta imune apresenta deficiência quantitativa ou funcional ${ }^{(14)}$.

São comuns lesões do tecido mole bucal e lesões ósseas, podendo ser as primeiras manifestações da doença. Estudo ${ }^{(15)}$ revelou que $29 \%$ do grupo de 45 crianças com histiocitose exibiram sintomas bucais no momento do diagnóstico e 45\% apresentaram manifestações bucais durante o curso natural da doença.

A histiocitose X está associada à formação de bolsas periodontais em meio anaeróbio, o que favorece a colonização de periodontopatógenos. As bactérias presentes nos sítios afetados são: $P$. gingivalis, $T$. forsythensis, $T$. denticola e $P$. intermedia. Esses micro-organismos induzem à síntese de interleucina-1 e prostaglandina-E2 em tecidos periodontais, associando-se à destruição óssea ${ }^{(14)}$.

Os sinais clínicos orais incluem alterações nos tecidos gengivais e nos tecidos de suporte ao redor dos dentes. Observamse como sinais precoces a presença de edema e de necrose gengival e, frequentemente, há um gosto ruim ou halitose. Ocorrem também, nos casos avançados, a formação de bolsas periodontais, grande destruição do osso alveolar e mobilidade dos dentes. Nos casos graves que não recebem tratamento periodontal, ocorre perda óssea extensa com exposição das raízes dos dentes, aumento de mobilidade, e esfoliação prematura dos dentes decíduos. Radiograficamente, os dentes afetados, frequentemente os molares, apresentam uma característica de imagem descrita como "dentes flutuantes ${ }^{(13)}$ ".

\section{Síndrome de Down}

Indivíduos afetados pela síndrome de Down apresentam com frequência uma forma agressiva de doença periodontal, que ocorre devido à resposta imunológica ou à fragilidade dos tecidos periodontais ${ }^{(16-17)}$. A destruição periodontal atinge tanto a dentição decídua quanto a permanente de forma generalizada, apesar de as lesões serem mais graves em torno dos dentes anteroinferiores ${ }^{(18)}$.

Dentre as manifestações bucais mais comuns, destacam-se as anomalias dentárias, a macroglossia, a língua fissurada, o palato ogival e a má oclusão, além de um maior número de cáries dentárias e maior suscetibilidade à doença periodontal ${ }^{(19)}$. A periodontite agressiva é frequente, com uma progressão mais rápida e extensa quando comparada aos pacientes normais ${ }^{(20)}$. Outras condições periodontais também encontradas são a gengivite marginal, a recessão gengival, as perdas ósseas com supuração abundante, o envolvimento da área de furca na região dos molares e a frequente perda de inserção, seguida de perda dentária na região anterior da mandíbula ${ }^{(19)}$.

Por apresentarem deficiências motora, neurológica e hipotonia muscular, os indivíduos com síndrome de Down têm dificuldade na higienização bucal, levando ao acúmulo do biofilme bacteriano, que aumenta a suscetibilidade à doença periodontal. Entretanto, a deficiência imunológica é o fator que contribui para a evolução da doença periodontal, já que, nesses casos, o organismo apresenta dificuldades de combater as bactérias presentes no biofilme dental ${ }^{(20)}$. A redução numérica dos linfócitos e os defeitos funcionais de quimiotaxia e fagocitose celular dos neutrófilos e monócitos constituem as alterações mais comumente observadas na resposta imunológica destes pacientes, o que os torna altamente suscetíveis ao desenvolvimento da doença periodontal ${ }^{(20)}$.

Além das alterações imunológicas, outros fatores que explicam a alta prevalência da doença periodontal e o aumento da sua gravidade incluem a má oclusão, a colonização precoce de periodontopatógenos e a higiene oral insatisfatória ${ }^{(7,18-19)}$.

\section{Síndrome de Papillon-Lefèvre}

A síndrome de Papillon-Lefevre é uma doença hereditária rara, com característica autossômica recessiva, que afeta aproximadamente uma pessoa a cada um milhão. Leva ao aparecimento de hiperqueratose palmoplantar e, ocasionalmente, nos joelhos e cotovelos, além de alterações na quimiotaxia de neutrófilos, com maior suscetibilidade às infecções ${ }^{(11)}$.

A periodontite agressiva e a inflamação gengival grave são achados frequentes, sendo os dentes decíduos e permanentes comumente perdidos devido à doença periodontal avançada ${ }^{(6)}$. À medida que os dentes erupcionam, os tecidos periodontais apresentam-se alterados, ocorrendo inicialmente inflama- 
ção gengival, representada clinicamente por sangramento seguido de supuração, com posterior formação de bolsas periodontais, mobilidade dentária e esfoliação espontânea dos dentes, associada ou não à reabsorção radicular. Após a perda prematura dos dentes decíduos, os tecidos cicatrizam rapidamente, permanecendo saudáveis até a erupção dos permanentes, quando o processo inflamatório se instala novamente, levando também à perda de toda a dentição durante a adolescência ${ }^{(13)}$. Entretanto, de acordo com alguns autores $^{(21)}$, um rigoroso controle do biofilme bacteriano e consultas regulares de manutenção podem, em alguns casos, prevenir a perda dos dentes, enquanto a remoção dos dentes decíduos também pode permitir a manutenção da dentição permanente.

Os mecanismos envolvidos estão relacionados não apenas a alterações imunológicas, mas também a alterações nos tecidos periodontais e à presença de $A$. actinomycetemcomitans. Esse micro-organismo é responsável pela produção de uma proteína tóxica de $116-\mathrm{kDa}$ denominada leucotoxina, que possui grande capacidade de destruir os leucócitos ${ }^{(22)}$, o que aumenta a predisposição para a manutenção da infecção periodontal $^{(23)}$.

\section{Síndrome de Ehlers-Danlos}

A síndrome de Ehlers-Danlos (SED) consiste em um grupo de displasias do tecido conjuntivo com características genéticas autossômicas dominantes que afetam a síntese do colágeno. As manifestações clínicas incluem hiperextensibilidade e fragilidade da pele, hipermobilidade das articulações, deformidades do esqueleto, fragilidade ocular, tendência ao sangramento ${ }^{(11)}$.

Sob o ponto de vista periodontal, frequentemente há periodontite agressiva, recessão gengival e perda precoce dos dentes, sendo tais condições relacionadas ao defeito na síntese de colágeno, que compromete o periodonto ${ }^{(6)}$. O mecanismo das alterações dos tecidos conectivos é explicado pelo fato de existir uma anomalia genética no colágeno tipo III, presente em aproximadamente $20 \%$ do total de colágeno do ligamento periodontal, afetando a inserção periodontal e comprometendo, portanto, a integridade do periodonto, o que eleva a suscetibilidade a doenças periodontais ${ }^{(13)}$.

A síndrome de Ehlers-Danlos é um grupo heterogêneo de pelo menos dez tipos ( $\mathrm{I}$ ao $\mathrm{X}$ ) distintos de doenças. $\mathrm{O}$ início da periodontite foi reconhecido no tipo VIII, o qual também é caracterizado pela hiperextensibilidade da pele, por lesões equimóticas da pré-tíbia, presença de cicatrizes e hipermobilidade das articulações, que varia de mínima para moderada. A presença de doença periodontal também tem sido relacionada como um dos componentes do tipo IV, fortemente associado ao defeito no colágeno ${ }^{(3)}$.

\section{Síndrome de Chédiak-Higashi}

A síndrome de Chédiak-Higashi é uma doença autossômica recessiva em que os leucócitos são caracterizados por um aumento anormal dos grânulos dos granulócitos, adesão diminuída e degranulação defeituosa. Os sinais clínicos incluem albinismo oculocutâneo, estrabismo, fotofobia, infecções cutâneas e respiratórias recorrentes e episódios febris frequentes ${ }^{(6)}$. Na cavidade bucal, encontram-se alterações como gengivite e periodontite. A forma de destruição periodontal avançada, com perda de suporte ósseo ao redor dos dentes, mobilidade dental e a ocorrência de esfoliação precoce dos dentes é um achado comum ${ }^{(13,24)}$.

Em portadores dessa síndrome, a inflamação periodontal está associada a uma microbiota anaeróbia, com presença de processos purulentos. Há um grande número de espiroquetas nos sítios inflamados, com alta atividade proteolítica, o que facilita a aderência bacteriana. Adicionalmente, existem alterações de origem lisossomial no interior de granulócitos, monócitos e linfócitos. Os neutrófilos apresentam alterações na quimiotaxia e na capacidade bactericida. Essas alterações imunológicas implicam maior suscetibilidade ao desenvolvimento de periodontite agressiva, visto que a evolução da doença periodontal é largamente dependente da resposta imune do indivíduo ${ }^{(13,25)}$.

\section{Neutropenia}

A neutropenia faz parte de um grupo de doenças que apresentam um decréscimo do número de neutrófilos polimorfonucleares no sangue periférico. As formas que se relacionam com alterações bucais são: agranulocitose, neutropenia cíclica, neutropenia crônica benigna de criança, neutropenia crônica idiopática e neutropenia benigna familiar ${ }^{(26)}$. As manifestações periodontais encontradas relacionam-se com o grau de neutropenia. Casos leves podem levar ao surgimento de alterações nos tecidos gengivais, com o aparecimento da gengivite ulcerativa, caracterizada pela presença de vermelhidão, sangramento, úlceras e dor ${ }^{(21)}$. Nos casos graves, pode afetar os tecidos de suporte dos dentes, com perda óssea e formação de bolsa, caracterizando-se como uma periodontite agressiva $^{(27)}$.

Devido à redução no número de neutrófilos, os indivíduos apresentam alterações na capacidade de resposta imune, o que os predispõe ao desenvolvimento de infecções 
bacterianas. Os neutrófilos são células intimamente relacionadas com o controle e eliminação de micro-organismos patogênicos. As deficiências quantitativas e funcionais dos neutrófilos se traduzem em processos infecciosos recorrentes. Sendo a doença periodontal uma entidade infecciosa desencadeada pela presença do biofilme bacteriano, os indivíduos portadores de neutropenia apresentam maior risco de desenvolve-la ${ }^{(25)}$.

A periodontite associada à neutropenia e agranulocitose pode ter início durante ou imediatamente após a erupção dos dentes decíduos de forma generalizada ou localizada. $\mathrm{Na}$ forma generalizada da doença, há inflamação exacerbada, seguida de destruição rápida de osso alveolar, o que afeta todos os dentes decíduos. A dentição permanente pode ou não ser acometida. $\mathrm{O}$ exame radiográfico revela a presença de perdas ósseas generalizadas ao redor dos dentes e entre as raízes na área da furca. $\mathrm{Na}$ forma localizada, somente alguns dentes são afetados, a inflamação dos tecidos gengivais é mais leve e a destruição óssea não é tão rápida quanto na forma generalizada. No estudo radiológico, observam-se perdas ósseas ao redor de dentes e envolvimento de furca ${ }^{(26)}$. A ocorrência destas perdas ósseas é notada nos primeiros molares e nos incisivos ${ }^{(21)}$.

\section{Deficiência de adesão dos leucócitos}

A deficiência na adesão de leucócitos é uma alteração autossômica recessiva na qual a adesão de leucócitos está comprometida, dificultando a sua saída dos vasos sanguíneos para o sítio de infecção ${ }^{(6)}$. Os neutrófilos são incapazes de aderirem à superfície do endotélio por uma alteração nas integrinas e/ou selectinas. Os polimorfonucleares não migram até o foco infeccioso e, em consequência, há elevação dos níveis de neutrófilos circulantes, disseminando os processos infecciosos e limitando a cicatrização. Desse modo, os pacientes que apresentam essa alteração mostram uma resposta imunológica deficiente, sendo mais suscetíveis às infecções recorrentes e apresentando reparo tecidual alterado ${ }^{(25)}$.

Como alterações bucais, podem ser encontradas: inflamação gengival grave, proliferação gengival, formação de fissuras gengivais, perda óssea alveolar e perda de dentes decíduos e permanentes ${ }^{(21)}$. Pode ser observada, também, uma forma avançada de doença periodontal, durante ou imediatamente após a erupção dos dentes decíduos, com inflamação exacerbada, proliferação dos tecidos gengivais e rápida destruição óssea ao redor dos dentes. Além destas manifestações, pode-se encontrar estomatite, ulcerações da mucosa e celulites faciais ${ }^{(13)}$.

\section{Leucemias}

As leucemias compreendem o grupo de neoplasias malignas caracterizadas por proliferação progressiva e descontrolada dos leucócitos. A classificação varia de acordo com o tipo celular primariamente envolvido (mieloide ou linfoide) e com o curso da doença (aguda ou crônica) ${ }^{(28)}$. Na leucemia, há substituição dos elementos da medula óssea por células leucêmicas, com alteração da produção normal de células vermelhas, brancas e plaquetas, levando à anemia, redução do número de células brancas não-neoplásicas e trombocitopenia ${ }^{(28)}$.

As manifestações bucais em crianças são mais frequentemente encontradas nas leucemias linfocíticas e de curso agudo, sendo mais raras na leucemia crônica. Dentre essas manifestações, destacam-se: sangramento gengival, formação de petéquias na mucosa alveolar, crescimento gengival, ulcerações e infecções ${ }^{(28)}$.

O sangramento gengival encontra-se relacionado à trombocitopenia, sendo mais frequente no sulco gengival, mesmo na ausência de gengivite detectável clinicamente ${ }^{(29,30)}$. A tendência ao sangramento também pode ser observada na mucosa bucal, manifestada em forma de petéquias ${ }^{(28)}$. O sangramento bucal tem sido relatado em $17 \%$ dos pacientes portadores de leucemia aguda e em $4,4 \%$ dos portadores de leucemia crônica ${ }^{(30)}$.

A ocorrência de crescimento gengival encontra-se relacionada à infiltração de células leucêmicas no tecido conjuntivo gengival, levando ao surgimento de bolsas periodontais. Clinicamente, a gengiva apresenta uma coloração vermelhoazulada e cianótica, com arredondamento e perda da tensão da margem gengival. As alterações são mais comuns na papila interdental e, em alguns casos, a gengiva pode chegar a cobrir parte da coroa dos dentes. Estas áreas aumentadas de volume, por serem de difícil higiene, permitem o acúmulo de biofilme periodontopatogênico, o que possibilita a instalação da gengivite e contribui para o aumento do volume gengival $^{(31)}$.

Também se pode haver, na cavidade oral dos indivíduos leucêmicos, ulcerações e infecções dos tecidos bucais em decorrência da granulocitopenia secundária à leucemia, com diminuição da resistência do hospedeiro aos microorganismos oportunistas ${ }^{(30)}$. A infecção bacteriana pode ser primária ou resultar de um agravamento de alteração periodontal pré-existente. Manifestação de gengivite ulcerativa necrosante, ou seja, gengivite com necrose da papila interdentária, é observada em pacientes terminais com leucemia aguda. 


\section{Aids}

A síndrome da imunodeficiência adquirida (Aids) é definida como uma entidade patológica causada pela infecção por retrovírus - o vírus da imunodeficiência adquirida $(\mathrm{HIV})^{(32)} \mathrm{e}$ sua frequência vem aumentando entre crianças e adolescentes desde $1983^{(28)}$. As complicações sistêmicas mais comuns da Aids são: hepatomegalia, diarreia, pneumonia, infecções recorrentes e desordens neurológicas. Manifestações bucais, como periodontopatias, também são detectadas e se manifestam como eritema gengival linear, gengivite ulcerativa necrosante e periodontite ulcerativa necrosante ${ }^{(28)}$.

A gengivite e o eritema gengival linear são as condições clínicas orais mais comumente descritas em crianças e adolescentes HIV-positivos ${ }^{(33)}$. No entanto, há também a presença de periodontite em crianças e adolescentes infectados pelo $\mathrm{HIV}^{(28,34,35)}$. A doença periodontal pode ocorrer entre indivíduos portadores do HIV em todas as faixas etárias, mas a suscetibilidade à infecção periodontal aumenta à medida que o sistema imune se torna mais comprometido. Indivíduos com baixa porcentagem de linfócitos T-CD4 apresentam risco significativamente maior para o estabelecimento e a progressão de periodontite ${ }^{(36,37)}$. Os linfócitos T-CD4 iniciam e ajudam nas respostas imunes ao fornecer sinais proliferativos e de diferenciação. Consequentemente, com a redução no número dessas células, há uma deficiência na resposta imune, facilitando o processo de instalação da doença periodontal.

\section{Discussão}

A literatura demonstra que há relação entre doenças periodontais e doenças sistêmicas em crianças e adolescentes. Estes achados incluem desde a presença da gengivite até problemas mais avançados como periodontite agressiva e perda precoce de dentes. A ocorrência de doenças periodontais nestes indivíduos encontra-se relacionada às deficiências imunológicas que interferem na resposta do hospedeiro frente à presença de patógenos periodontopatogênicos existentes no biofilme dental ${ }^{(11,13,14,20,25,30,36)}$, levando a perdas ósseas e dentárias, e também se relaciona a alterações na síntese de colágeno ${ }^{(6)}$ e à hipofosfatasia cementária ${ }^{(12)}$. Nesse sentido, torna-se importante o desenvolvimento de estratégias voltadas para prevenção, diagnóstico precoce e terapêutico, buscando reduzir os problemas periodontais. Tais estratégias devem ser estruturadas com uma visão mais ampla, voltadas não só para a redução de perdas dentárias, mas também para fatores que possam contribuir para o controle da doença sistêmica destes indivíduos. A presença da infecção periodontal pode interferir no controle imunológico, dificultando a manutenção da saúde sistêmica. A perda de dentes pode dificultar a mastigação e interferir no controle nutricional.

$\mathrm{O}$ interesse pela relação doença periodontal e doença sistêmica passou a ser mais evidente nos anos 1990, com a introdução da visão da medicina periodontal. Estudos nesta área têm evidenciado a importância da saúde periodontal para a saúde sistêmica. Embora a maioria dos trabalhos esteja voltada para a população adulta, é crescente o interesse em avaliar também a população jovem ${ }^{(38,39)}$. Por serem doenças raras, como no caso das síndromes, os estudos em crianças e adolescentes tornam-se difíceis. Entretanto, dada a ocorrência de problemas periodontais mais agressivos nestes indivíduos, é necessário que mais estudos sejam desenvolvidos nesta área. Também é importante que o planejamento terapêutico dos pacientes seja feito com uma visão multidisciplinar entre a Medicina e a Odontologia.

Com a constatação do aumento do risco de doenças periodontais em crianças e adolescentes portadores de doenças sistêmicas, o pediatra pode contribuir para a redução destes problemas. Isto pode ser feito por meio do encaminhamento do paciente para uma avaliação periodontal tão logo seja feito o diagnóstico da doença sistêmica. Por outro lado, o acompanhamento destes indivíduos pelo periodontista poderá reduzir a infecção periodontal e as perdas dentárias, contribuindo para o controle sistêmico.

\section{Conclusões}

A ocorrência de alterações periodontais é observada com frequência em crianças e adolescentes com alterações sistêmicas ${ }^{(6-8,10-37)}$. A literatura evidenciou que as alterações periodontais manifestam desde uma inflamação gengival até as formas mais destrutivas, como a periodontite agressiva, levando, em alguns casos, à esfoliação precoce de dentes. Esses achados são importantes para reforçar a necessidade de incorporar, no planejamento terapêutico desses pacientes, cuidados odontológicos que visem a prevenir e controlar a infecção periodontal, reduzindo assim perdas dentárias e infecções, o que pode contribuir para a manutenção da saúde sistêmica. 


\section{Referências bibliográficas}

1. Hart TC, Kornman KS. Genetic factors in the pathogenesis of periodontitis. Periodontol 2000 1997;14:202-15.

2. Page RC. The pathobiology of periodontal diseases may affect systemic diseases: inversion of a paradigm. Ann Periodontol 1998;3:108-20.

3. Hart TC, Atkinson JC. Mendelian forms of periodontitis. Periodontol 2000 2007; 45:95-112.

4. Kornman KS, Crane A, Wang HY, di Giovine FS, Newman MG, Pirk FW et al. The interleukin-1 genotype as a severity factor in adult periodontal disease. J Clin Periodontol 1997;24:72-7.

5. Genco RJ, Christersson LA, Zambon JJ. Juvenile periodontitis. Int Dent J 1986;36:168-76.

6. Lagervall M, Jansson L, Bergström J. Systemic disorders in patients with periodontal disease. J Clin Periodontol 2003;30:293-9.

7. Morgan $\mathrm{J}$. Why is periodontal disease more prevalent and more severe in people with Down syndrome. Spec Care Dentist 2007;27:196-201.

8. Kinane DF. Periodontitis modified by systemic factors. Ann Periodontol 1999;4:54-64.

9. Michalowicz BS. Genetic and heritable risk factors in periodontal disease. J Periodontol 1994;65 (5 Suppl):479-88.

10. Page RC. The pathobiology of periodontal diseases may affect systemic diseases: inversion of a paradigm. Ann Periodontol 1998;3:108-20.

11. Kinane DF, Marshall GJ. Periodontal manifestations of systemic disease. Aus Den J 2001;46:2-12.

12. Bimstein E, Wignall W, Cohen D, Katz J. Root surface characteristics of children teeth with periodontal diseases. J Clin Pediatr Dent 2008;32: 101-4.

13. Grollmus ZC, Chávez MC, Donat FJ. Periodontal disease associated to systemic genetic disorders. Med Oral Patol Oral Cir Bucal 2007;12: E211-5.

14. Torrungruang K, Sittisomwong S, Rojanasomsith K, Asvanit P, Korkongwisarut D, Vipismakul V. Langerhans'cell histiocytosis in a 5-year-old girl: evidence of periodontal pathogens. J Periodontol 2006;77:728-33.

15. Filocoma D, Needleman HL, Arceci R, Gelber RD, Donnelly M. Pediatric histiocytosis. Characterization, prognosis, and oral involvement. Am J Pediatr Hematol Oncol 1993;15:226-30.

16. Dow RS. A preliminary study of periodontoclasia in Mongolian children at Polk State School. Am J Ment Defic 1951;55:535-8.

17. Cohen MM, Winer RA, Schwartz S, Shklar G. Oral aspects of mongolism. I. Periodontal disease in mongolism. Oral Surg Oral Med Oral Pathol 1961;14: 92-107.

18. Yoshihara T, Morinushi T, Kinjyo S, Yamasaki Y. Effect of periodic preventive care on the progression of periodontal disease in young adults with Down's syndrome. J Clin Periodontol 2005;32:556-60.

19. López-Pérez R, Borges-Yáñez SA, Jiménez-García G, Maupomé G. Oral hygiene, gingivitis and periodontitis in persons with Down syndrome. Spec Care Dentist 2002;22:214-20.

20. Bagić I, Verzak Z, Cuković-Cavka S, Brkić H, Susić M. Periodontal conditions in individuals with Down's syndrome. Coll Antropol 2003;27:75-82.
21. Seymour GJ, Ford PJ, Cullinan MP, Leishman S, Yamazaki K. Relationship between periodontal infections and systemic disease. Clin Microbiol Infect 2007;13 (Suppl 4):3-10.

22. Canger EM, Celenk P, Devrim I, Yenisey M, Gunhan O. Intraoral findings of Papillon-Lefèvre syndrome. J Dent Child (Chic) 2008;75:99-103.

23. Yang Y, Bai X, Liu H, Li L, Cao C, Ge L. Novel mutations of cathepsin C gene in two Chinese patients with Papillon-Lefèvre syndrome. J Dent Res 2007;86:735-8.

24. Delcourt-Debruyne EM, Boutigny HR, Hildebrand HF. Features of severe periodontal disease in a teenager with Chédiak-Higashi syndrome. J Periodontol 2000;71:816-24

25. Dios PD, Hermida AO, Feijoo JF. Alteraciones cuantitativas y funcionales de los neutrófilos. Med Oral 2002;7:206-21.

26. Zaromb A, Chamberlain D, Schoor R, Almas K, Blei F. Periodontitis as a manifestation of chronic benign neutropenia. J Periodontol 2006;77:1921-6.

27. Kalkwarf KL, McLey LL. Neutropenias and neutrophil dysfunction in children: relationship to periodontal diseases. J West Soc Periodontol Periodontol Abstr 1984;32:5-19.

28. Toledo BE, Mendes MM, Moreira Neto JJ. Alterações sistêmicas relacionadas com periodontites de estabelecimento precoce. Rev Periodontia SOBRAPE 1997;6:31-34.

29. Nasim VS, Shetty YR, Hegde AM. Dental health status in children with acute lymphoblastic leukemia. J Clin Pediatr Dent 2007;31:210-3.

30. Lynch MA, Ship II. Initial oral manifestations of leukemia. J Am Dent Assoc 1967;75:932-40.

31. Viera NT, Rojas-de-Morales T, Navas RM, Zambrano OR, Paz-de-Gudino M Gingivitis and anti-neutrophil cytoplasmic antibodies in children and adolescents suffering from leukemia. Med Oral Patol Oral Cir Bucal 2004;9:399-402.

32. Patton LL, van der Horst C. Oral infections and other manifestations of HIV disease. Infect Dis Clin North Am 1999;13:879-900.

33. Costa CC, Cardoso L, Resende GB, Bosco VL. Manifestações periodontais em crianças e adolescentes HIV positivos e HIV negativos institucionalizados. Arq Odontol 2003;39:5-11.

34. Shangase L, Feller L, Blignaut E. Necrotising ulcerative gingivitis/periodontitis as indicators of HIV-infection. SADJ 2004;59:105-8.

35. Greenspan JS. Sentinels and signposts: the epidemiology and significance of the oral manifestations of HIV disease. Oral Dis 1997;3(Suppl 1):S13-7.

36. Feller L, Lemmer J. Necrotizing periodontal diseases in HIV-seropositive subjects: pathogenic mechanisms. J Int Acad Periodontol 2008;10:10-5.

37. Okunseri C, Badner V, Wiznia A, Rosenberg M. Prevalence of oral lesions and percent $\mathrm{CD} 4^{+} \mathrm{T}$-lymphocytes in HIV-infected children on antiretroviral therapy. AIDS Patient Care STDS 2003;17:5-11.

38. Romito GA, Garcia DB, Pustiglioni FE. Periodontites de incidência precoce - necessidade de um diagnóstico precoce. Rev Periodontia SOBRAPE 2002;13:5-10.

39. Barrêtto EP, Costa FO, Pordeus IA. Periodontites agressivas em crianças e adolescentes: existe um padrão intrafamiliar? J Bras Odontopediatr Odontol Bebê 2002;5:201-8. 